\title{
Obstacles for learning introductory college physics in Japan: Identifying factors from a case study
}

\author{
Sachiko Tosa \\ Faculty of Education, Niigata University, \\ Ikarashi 2-no-cho, 8050 banchi, Nishi-ku, Niigata, Niigata 950-2181, Japan
}

\begin{abstract}
It is often the case that students who did not take a high school physics course have difficulties in understanding content in college introductory physics courses. This trend in the U.S was examined in Japan. In this study factors that have strong correlations with the level of HS physics were identified for Japanese students in a lecture-type introductory physics course for science education majors $(\mathrm{N}=22)$. We found that physics grades as well as FCI scores had a strong correlation with the level of high-school. We conducted semi-structured interviews with 4 students who did not take HS physics and were having serious problems in following the content of the course. Our analysis revealed their high need to be prompted as a common feature when they tried to explain the motion of an object on a slope. We argue that interactive teaching strategies would be an effective way to help such students.
\end{abstract}

PACS: $01.40 . \mathrm{Fk}$

\section{INTRODUCTION}

High school physics is found to play an important role for the success of college physics in the U.S. [1]. In Japan also, one of the reasons for the low level of college physics is said to be the diversity of the requirements for taking science courses in high school [2]. In a survey conducted in 2005 for 10,000 college students in Japan [3], a half of the students (48.7\%) did not take a physics course in high school. Even among students majoring science and math fields, one third of them $(32.5 \%)$ did not take high-school physics. This percentage is doubled for students majoring literature (64.2\%). It is not difficult to imagine that those students who did not take a physics course in high school are less prepared for learning physics in college than those who took physics in high school.

However, it is not certain that the lack of HS physics is the only reason accounting for the low level of physics understanding in college. If that is the case, strategies such as offering remedial physics courses to cover the content of high school physics would be effective. However, if there are other factors that make understanding college physics difficult, offering additional remedial courses might not be effective enough to solve the problem. Students who did not take HS school physics must have their own reasons for not choosing physics in high school. There could be some factors that we oversee under the label of "no HS physics". Under the circumstance, it is important to investigate the situation in detail and identify factors that make college physics difficult to understand on an individual basis.

In this study, correlations between student performance of an introductory college physics course (mechanics) and various factors were investigated at the beginning and end of a semester. The target population was 22 college students majoring science education in a Japanese university. These students are pre-service teachers in elementary and middle schools. Unlike students in science and engineering departments, science education majors often skip taking physics courses in high school [3]. The level of high-school physics that students completed varies for this population. It is expected that by finding the correlation among their college physics performance and the level of high-school physics and other factors, we would be able to identify where the problem. Furthermore, we use interview techniques to help us dig the problem deeper and identify critical points that are related to difficulties for students who did not take a HS physics course.

Student misconcepts in physics are well studied in college physics education [4]. However, few research studies were conducted to identify factors that make understanding college physics difficult in Japan. If such factors are identified, we would be able to develop and implement concrete strategies to help the situation. The following two research questions guided this study: (1) What are the factors which have strong correlations with student performance in an introductory college physics course (mechanics) in Japan?, (2) What are common features among students who have serious difficulties in understanding the content in the introductory college physics course? The purpose of this study is to investigate the situation in detail by conducting a research study on students in science education and to propose strategies for improving the situation.

\section{THEORETICAL FRAMEWORK}

Theoretical framework that supports this study is constructivism in science education [5]. According to the approach taken by constructivists in science education, the learner acquires knowledge about natural phenomena by actively constructing his or her viable interpretation of the phenomena through hands-on and minds-on activities. 
It is considered that one-way transmission of information from the teacher to students would not be effective enough for promoting knowledge construction. Constructivists view knowledge construction as a process in which new information is integrated with students' prior knowledge. Instructors are expected to implement various instructional strategies to promote student knowledge construction. Scaffolds from teachers are expected to help students construct scientific knowledge. Explanations presented by peers would also help students look at the phenomena through a different view. Such active learning strategies are encouraged by the Japanese government recently to be implemented especially in colleges [7].

\section{METHOD}

\section{A. Sample}

Participants of this study are sophomores majoring science education in a university in Japan $(\mathrm{N}=22)$. They took an introductory physics course (mechanics) in the spring semester 2014. Sample includes 14 male and 8 female students (Table 1). All the students took a calculus course as freshmen. Table 1 also shows the number of participants who completed a particular level of high-school physics. Note that there are 4 levels. General Science A includes energy as a topic, but no explicit physics content.

TABLE 1. Participants' gender and completed level of highschool physics $(\mathrm{N}=22)$.

\begin{tabular}{l|l|r}
\hline \multicolumn{1}{c|}{ Item } & \multicolumn{1}{|c|}{ Category } & \multicolumn{1}{c}{$\begin{array}{c}\text { Number of } \\
\text { students }\end{array}$} \\
\hline \multirow{2}{*}{ Gender } & $1=$ male & 14 \\
\cline { 2 - 3 } & $2=$ female & 8 \\
\hline \multirow{2}{*}{$\begin{array}{l}\text { Completed } \\
\text { level of } \\
\text { high-school } \\
\text { physics }\end{array}$} & $1=$ did not take physics & 1 \\
\cline { 2 - 3 } & $2=$ General Science $A$ & 6 \\
\cline { 2 - 3 } & $3=$ Physics I & 12 \\
\cline { 2 - 3 } & $4=$ Physics II & \\
\hline
\end{tabular}

\section{B. Introductory physics course}

The introductory physics class met once a week for a 90minute lesson. The course is calculus-based and consisted of 16 lessons (Table 2). The course requirements include 5 sets of homework (all numerical; $42 \%$ of the total grade), a final exam (numerical, 54\%), and attendance (4\%). The teaching style of the lessons was a traditional type in which the instructor explained the content didactically using the blackboard. Students were expected to listen to the instructor and take notes. Student presentation of their way of solving problems were included in some of the sessions. Student-tostudent discussions were not explicitly encouraged during the lesson.

\section{Research Method}

Data collected in this study were 1) grades of the first
TABLE 2. Content of the introductory college physics course.

\begin{tabular}{l|l}
\hline & \multicolumn{1}{|c}{ Content } \\
\hline 1 & FCI pre-test, Physical quantities and dimensions \\
\hline 2 & Vectors, balanced forces \\
\hline 3 & Newton's equation of motion \\
\hline 4 & $\begin{array}{l}\text { Projectile motion, simple harmonic oscillation, } \\
\text { friction }\end{array}$ \\
\hline 5 & Newton's laws of motion, circular motion \\
\hline 6 & Conservation of energy (1 dimension) \\
\hline 7 & Motion in a 1-dim potential well \\
\hline 8 & Line integration, work, conservative force \\
\hline 9 & $\begin{array}{l}\text { Partial differentiation, gradient, conservation of } \\
\text { energy (3 dimension) }\end{array}$ \\
\hline 10 & Universal gravity, pendulum \\
\hline 11 & $\begin{array}{l}\text { Cross product, rotational motion, angular } \\
\text { momentum }\end{array}$ \\
\hline 12 & 2-dim polar coordinate, area velocity \\
\hline 13 & Kepler's first and third laws \\
\hline 14 & Elliptic motion, Kepler's equation of motion \\
\hline 15 & Final exam \\
\hline 16 & Review of exam, FCI post-test, Lawson test \\
\hline
\end{tabular}

homework, 2) final grades of the calculus course completed in the previous semester, 3) FCI [6]pre-test scores, 4) final grades of the physics course, 5) FCI post-test scores, and 6) scores of Lawson test. Lawson test measures student scientific reasoning abilities [8]. The first homework includes 2 sets of numerical problems. One of them was used as an interview question. Its English version is shown in Fig. 1. It asks the motion of two blocks placed on a slope. Data were analyzed statistically.

To collect interview data, 4 students were identified as students who have difficulties in understanding the content of college physics. The criteria used for selecting students were 1) the score of FCI pre-test was lower than 10 out of 30 points, and 2) the grade of the first homework was lower than 10 out of 15 points. All 4 students were female. They took General Science A but not physics in high school. A semistructured interview with each of the students was conducted in Japanese in the middle of the semester. An English version of the protocol is shown in Table 3 .

Conversation between each of the participants and researcher during the interview was recorded and transcribed. Interview data consist of documents from 4 students. They were analyzed through a qualitative research method through coding [9]. Topics described by the participants in the interview were used as nodes for coding. When coding was finished for a document, its consistency was checked and nodes were merged or split as necessary. The analysis followed a recursive pattern until consistency was achieved for coding of all 4 documents. The following topics were identified as nodes: "current situation in class", "high school physics", "difficulties in understanding physics concepts", "problem-solving difficulties", "help from others", "desire to learn physics", and "suggestions for improving". Then, 
coded portions of the documents were tabulated according to the node. Descriptions from 4 students for each node were compared to find common features among them.

As shown in the figure below, Object A of mass $M_{A}$ and Object B of mass $M_{B}$ are placed on top of each other on a slope with angle $\theta$ from the horizontal plane. Object $A$ and Object B are staying still. Take the gravitational constant as $g$.

(a) Find the normal force $R_{A}$ and $R_{B}$.

(b) Find the friction force $F_{A}$ and $F_{B}$.

(c) Take $\mu_{1}$ and $\mu_{2}$ as the static friction coefficient between Objects A and B and between Object B and slope respectively. Find a set of conditions that hold for the two objects when they do not slide down.

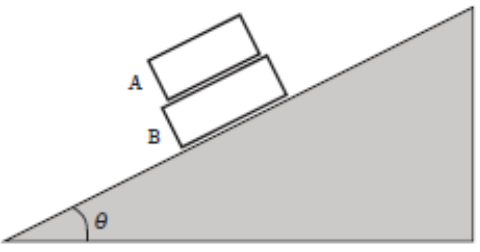

FIG 1. Physics problem used for interview.

TABLE 3. Interview protocol.

\begin{tabular}{l|l}
\hline Item & \multicolumn{1}{c}{ Question } \\
\hline 1 & $\begin{array}{l}\text { I understand that you are taking the introductory } \\
\text { physics course this semester. How is it going? Is it } \\
\text { going well or not-so-well? Would you describe } \\
\text { your situation? }\end{array}$ \\
\hline 2 & $\begin{array}{l}\text { Here is a copy of your first homework. Would you } \\
\text { describe what you knew and what you had a } \\
\text { difficulty with? }\end{array}$ \\
\hline 3 & $\begin{array}{l}\text { Where do you think your difficulties in learning } \\
\text { physics are coming from? }\end{array}$ \\
\hline 4 & $\begin{array}{l}\text { What would be helpful for improving the difficult } \\
\text { situation you are facing in learning physics in } \\
\text { introductory physics class? Would it be helpful for } \\
\text { you if pair talks or group problem-solving and } \\
\text { discussions are included in lessons? }\end{array}$ \\
\hline
\end{tabular}

\section{RESULT}

\section{A. Initial result}

Correlations among the initial physics performance on the first homework, grade of the mathematics course, FCI pre-test, gender, and the level of high-school physics were calculated. Pearson correlation coefficients between two of the factors are shown inside the box with bold lines in Table $4(\mathrm{~N}=22)$. The level of high-school physics has a strong correlation with FCI pre-test and initial physics grade.

\section{B. Results obtained at the end of semester}

At the end of the semester, three additional data sets were collected. Final grades were collected from all the students. Data on FCI post-test and Lawson test were collected from
20 students. Class average of the normalized gain calculated from the FCI pre and post-test scores was 0.13. In this study, FCI raw scores rather than normalized gains were focused so that we would be able to identify learning difficulties for low-performing students in a traditional physics course. Pearson correlation coefficients between two of the factors are shown outside of the box with bold lines in Table 4. The level of HS physics has a strong correlation with FCI posttest and physics final grade. Lawson test did not show strong correlations with any of the factors, indicating that student difficulties in physics are not related to their scientific reasoning abilities.

\section{Interview results}

Interviews were conducted with 4 students (Student A, B, $\mathrm{C}$, and D) in the middle of the semester. All 4 students did not take physics in high school. They described their current situation in the physics course as difficult. The situation was similar when they were taking a calculus course in the previous year. All 4 students said that they copy board writing mechanically without understanding the content during the lesson. They all mentioned their inability for solving physics problems given to them as homework. Student D described the situation as follows*:

"I took biology as science in high school. Not physics. It's been my problem for not getting mathematical ideas and it has been difficult for me to follow physics lectures. I could only copy board writing during class. It is hard to understand the meaning of what I copied after the lesson. When a problem is given as homework, I do not know what to do. Perhaps if I can follow what the instructor is doing in class, I think I would be able to solve those homework problems."

Other three students similarly described their difficult situation as "I do not have the basic understanding of physics" and "My brain does not contain the circuit for solving the physics problems."

During the interview, the participants solved the homework problem with the help of the researcher. The common physics and math difficulties that all 4 students had were 1) to draw a diagram to solve the problem, 2) to decompose a force into two components, 3) to understand why the force is decomposed into two components that are parallel and perpendicular to the plane of the slope, 4) to use trigonometry to express the components, 5) to understand what the normal force is, 6) to understand how the friction force works, and 7) to write an equation of motion using the force component. Even though they could not perform these activities by themselves, they were able to draw a diagram whey they were prompted to do so by the researcher. They were also able to decompose the gravitational force into two components and express the component forces using $\sin \theta$ and $\cos \theta$ when they were prompted step by step by the researcher. Fig. 2 shows such a diagram that Student B drew during the interview.

\footnotetext{
* Interview quotations presented in this paper were translated from Japanese to English by the researcher.
} 
TABLE 4. Correlations among various factors (initial results shown in the box with bold lines; $\mathrm{N}=22$ for the values inside the box with dashed lines, $\mathrm{N}=20$ for the values outside the box; statistically significant level: $*<0.05, \quad * *<0.01$; gender: $1=$ male, $2=$ female; level of high-school physics: $1=$ did not take physics, $2=$ General Science A, $3=$ Physics I, $4=$ Physics II)

\begin{tabular}{|c|l|l|l|l|l|l|l}
\hline & $\begin{array}{c}\text { Initial } \\
\text { physics }\end{array}$ & $\begin{array}{c}\text { Math final } \\
\text { grade }\end{array}$ & $\begin{array}{c}\text { FCI pre- } \\
\text { test }\end{array}$ & \multicolumn{1}{|c|}{ Gender } & $\begin{array}{c}\text { Physics } \\
\text { final grade }\end{array}$ & $\begin{array}{c}\text { FCI post- } \\
\text { test }\end{array}$ & $\begin{array}{c}\text { Lawson } \\
\text { test }\end{array}$ \\
\hline Level of HS physics & $0.473^{*}$ & 0.135 & $0.676^{* *}$ & -0.140 & $0.427^{*}$ & $0.781^{* *}$ & 0.325 \\
\hline Initial physics & - & $0.781^{* *}$ & $0.663^{* *}$ & $-0.547^{* *}$ & $0.639^{* *}$ & $0.536^{*}$ & 0.065 \\
\hline Math final grade & - & - & $0.487^{*}$ & $-0.625^{* *}$ & $0.482^{*}$ & 0.252 & -0.014 \\
\hline FCI pre-test & - & - & - & $-0.458^{*}$ & 0.382 & $0.784^{* *}$ & 0.116 \\
\hline Gender & - & - & - & - & -0.176 & -0.407 & -0.185 \\
\hline Physics final grade & - & - & - & - & - & 0.414 & -0.195 \\
\hline FCI post-test & - & - & - & - & - & - & 0.169 \\
\hline
\end{tabular}

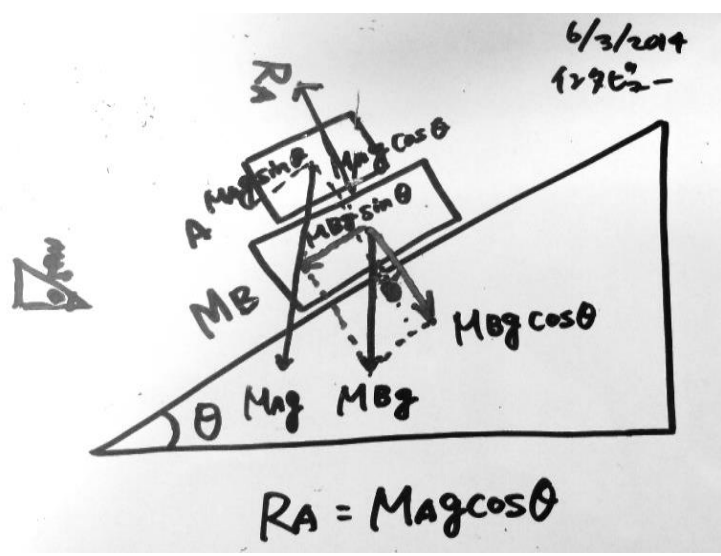

FIG. 2. Diagram drawn by a student who had difficulties. When prompted, the student was able to draw arrows to indicate the direction and magnitude of the forces. The student was also able to give a mathematical expression for each of the force components shown in the diagram. Interviewer's prompts are shown in a side way.

All 4 students expressed their reluctance to ask for help from others. Student A said "Even students who took physics in high school are having hard time solving homework problems. I hesitate to ask for help. I hesitate to ask them to spend time for me." Instead of asking others for help, they blame themselves for lack of studying. Student C said "I do not understand physics because I'm not studying hard enough." All 4 students were not seeking explicit help from others in spite of the continuing difficulties they were experiencing in math and physics classes. However, all 4 students mentioned their desire to understand physics. Student B said "it will be fun if I understand physics."

[1] P. M. Sadler, and R. H. Tai, Sci. Ed. 85, 111 (2001).

[2] Physics Research Committee, Science Council of Japan, Physics Research Committee Report (2000).

[3] Benesse Corporation, Report on the Survey Supported by the Ministry of Economics and Industry (2005).

[4] See for example, J. Clement, Am. J. Phys., 50, 66 (1982).

[5] C. T. Fosnot (Ed.) Constructivism-Theory, Perspectives,

\section{CONCLUSIONS}

This study found that the level of HS physics affects significantly on conceptual (FCI scores) as well as numerical (physics grades) understanding in a college introductory physics course for science education majors in Japan. The author acknowledges the fact that the sample size of 22 may be too small to draw any wide reaching conclusions about the population at large. However, this conclusion is consistent with the findings in the literature $[1,2]$. The importance of HS physics is reconfirmed.

This study also identified student difficulties in following mathematical steps in problem solving. When they were prompted, however, they were able to solve a problem. It seems that students who did not take a HS physics course were not just accustomed to the mathematical approach used in physics. Their need to be helped was demonstrated in this study.

We argue that interactive teaching method would be effective for helping those students during the class time. It would be helpful for these students to be given opportunities to express their difficulties and engage in solving problems by actively participating in group discussion. They would be able to get help from instructors and peers more easily in a class of active-learning style than in a class of traditional type. Outside class, such help as instructor's office hour and help desk would be useful for these students to ask for a help.

These preliminary findings from this study provide physics educators in Japan with useful information about the nature of difficulties that students who did not take HS physics have.

and Practice (Teachers College Press, New York, 2005). [6] D. Hestenes, M. Wells, and G. Swackhamer, Phys. Teach. 30, 141 (1992).

[7] Central Education Council of Japan, Report for Improving College Education (2012).

[8] A. E. Lawson, J. of Res. in Sci. Teaching, 15, 1 (1978).

[9] C. Glesne, Becoming Qualitative Researchers: An Introduction (Pearson Education, New York, 2006). 